Agronomía Costarricense 37(1): 61-69. ISSN:0377-9424 / 2013

www.mag.go.cr/rev_agr/index.html www.cia.ucr.ac.cr

\title{
RESISTENCIA GENÉTICA DE HÍBRIDOS DE TOMATE [Solanum lycopersicum L. (MILL.)] AL VIRUS DEL BRONCEADO (TSWV)
}

\author{
Julio Gabriel ${ }^{1 / *}$, Daniel Sanabria**, Silene Veramendi ${ }^{*}$ \\ Giovanna Plata*, Ada Angulo*, Mario Crespo*
}

Palabras clave: DAS-ELISA, severidad, homocigosis, heterocigosis, susceptibilidad, alelo. Keywords: DAS-ELISA, severity, homozygous, heterozygous, susceptibility, allele.

Recibido: 30/08/12

Aceptado: $11 / 12 / 12$

\section{RESUMEN}

La presente investigación se realizó en el invernadero y laboratorio de la Fundación PROINPA en Cochabamba - Bolivia en el 2012. El objetivo fue evaluar la resistencia y susceptibilidad de plantas a los virus Tomato spotted wilt virus - TSWV, Tomato cholorotic spot virus - TCSV y Groundnut ringspot virus - GRSV en 10 híbridos de tomate mediante evaluación fenotípica y del patrón molecular (marcador SCAR $\mathrm{Sw}$ - 421), que distingue los homocigotos y heterocigotos resistentes del susceptible. Los resultados mostraron que el marcador SW-421 se colocalizó con el gen Sw-5 de resistencia a TSWV. Se observó la presencia de la banda de resistencia (R) para TSWV a 940 bp en las variedades PROINPA 2 (Aguaí) y PROINPA 9 (Bonita) en estado homocigoto dominante (Sw-5/Sw-5). Las variedades PROINPA 1 (Andinita), PROINPA 3 (Arami), PROINPA 4 (Yara), PROINPA 5 (Pintona), PROINPA 6 (Jasuka), y PROINPA 10 (Bola Pera), mostraron la banda resistencia $(\mathrm{H})$ a TSWV a 900-940 bp en estado heterocigoto $\left(\mathrm{Sw}-5 / \mathrm{Sw}-5^{+}\right)$. Solamente la variedad PROINPA 7 (Redonda), el padre 71 89S LACHING SW-5 y la variedad Shannon mostraron el gen de susceptibilidad (S) al TSWV a 900 bp en estado homocigoto recesivo $\left(\mathrm{Sw}-5^{+} / \mathrm{Sw}-5^{+}\right)$. Los análisis de severidad y de DAS-ELISA fueron confirmados con el análisis molecular.

\footnotetext{
1/ Autor para correspondencia. Correo electrónico: j.gabriel@proinpa.org Fundación PROINPA, Casilla 4285, Cochabamba, Bolivia.
}

\begin{abstract}
Genetic resistance of tomato hybrids [Solanum lycopersicum L. (Mill.)] to tomato spotted wilt virus (TSWV). This research was conducted at the PROINPA Foundation's greenhouse and laboratory in Cochabamba, Bolivia in 2012. Its objective was to evaluate the resistance and susceptibility to Tomato spotted wilt virus - TSWV, Tomato cholorotic spot virus - TCSV and Groundnut ringspot virus - GRSV in 10 tomato hybrids. Phenotypic and molecular pattern (SCAR marker SW-421) evaluations were performed in order to differentiate homozygous and heterozygous resistant from susceptible plants. Results showed that molecular marker Sw421 is co-located with the TSWV-resistance Sw-5 gene. A TSWV-resistance band (R) was observed at 940 bp and showed the homozygous presence of the Sw-5 allele (Sw-5/Sw-5) in PROINPA 2 (Aguai) and PROINPA 9 (Bonita) varieties. PROINPA 1 (Andinita), PROINPA 3 (Arami), PROINPA 4 (Yara), PROINPA 5 (Pintona), PROINPA 6 (Jasuka) and PROINPA 10 (Bola Pera) varieties, showed a TSWV resistance band $(\mathrm{H})$ at 900 $940 \mathrm{bp}$ in the heterozygous state $\left(\mathrm{Sw}-5 / \mathrm{Sw}-5^{+}\right)$. Only PROINPA 7 (Redonda), the male parent 71 LACHING 89S Sw-5 and the variety Shannon showed TSWV susceptibility gene (S) at $900 \mathrm{bp}$ in the homozygous-recessive state $\left(\mathrm{Sw}-5^{+} / \mathrm{Sw}-5^{+}\right)$. The results of the severity analysis and of DASELISA were confirmed by the molecular analysis.

\footnotetext{
** Facultad de Bioquímica y Farmacia de la Universidad Mayor de San Simón, Cochabamba, Bolivia.
} 


\section{INTRODUCCIÓN}

Las enfermedades causadas por virus son consideradas un obstáculo para el cultivo del tomate [(Solanum lycopersicum L. (Mill,)] ya que causan pérdidas significativas en la producción. En Bolivia, como lo indica una reciente investigación (Plata 2011) el Tomato spotted wilt virus - TSWV, el Tomato cholorotic spot virus - TCSV y el Groundnut rigspod virus - GRSV son los más importantes virus causantes del Tospovirus (virus del bronceado o peste negra), y confirma lo ya indicado por Abad (2005). Similar situación se ha reportado en otros países como Brasil, donde además tienen al Crysanthemum stem necrosis virus - CSNV que afecta al tomate (Lima et ál. 2002, Ferraz et ál. 2004, Lau et ál. 2006).

Se debe mencionar que la resistencia genética del tomate al virus TSWV se ha visto en distintas accesiones en el género Lycopersicum (García y Lozoya 2004, Robertson y Labato 2007). Algunos alelos de resistencia se introdujeron en cultivares comerciales, como el Rey de los Tempranos que tiene resistencia de Lycopersicum esculentum y Stevens que tiene resistencia de L. peruvianum. Estos cultivares son las 2 principales fuentes de resistencia utilizadas en el control genético del TSWV en los programas de mejoramiento en Brasil y otros países (Ferraz 2004, Rodrigues do Nascimento et ál. 2009). La resistencia en el cultivar Stevens es controlado por un gen, denominado Sw-5 con interacción alélica dominante (Rosello et ál. 1998, Stevens et ál. 1992, Juliatti y Maluf 1995), mientras que para el cultivar Rey de los Tempranos la resistencia es controlada por al menos 1 a 3 genes con interacción semi-alélica dominante (Juliatti y Maluf 2005, Erico et ál. 2009).

Se atribuyeron muchas ventajas a la selección asistida por marcadores moleculares (SAMM) (Moon y Nicholson 2007, Foolad 2007) como efecto de la ausencia del efecto medio ambiental y la independencia del desarrollo de la planta, que es considerado por algunos autores como uno de los principales problemas en la selección de resistencia o de plantas inmunes a los virus a través de la selección fenotípica (Lanza et ál. 2000, Ribeiro et ál. 2006).

Referente a la resistencia al virus es posible piramidar múltiples alelos de resistencia. En el caso de TSWV, el marcador SCAR SW-421 podría ser una herramienta importante para la SAMM. Varios marcadores moleculares asociados al gene-virus de resistencia se han identificado, aunque su uso no ha sido frecuente cuando no están estrechamente asociadas al gen con un alelo interés (Silva et ál. 2003, Santos 2004, Ribeiro et ál. 2006). La distancia entre el Sw-421 y el alelo marcador Sw-5 es menor que 1,0 cM (Stevens et ál. 1991), y esto permite la selección de la Sw-5 alelo con un buen margen de seguridad.

Stevens et ál. (1995) desarrollaron el marcador UBC-421 de un RAPD (Random amplified polymorphic DNA) que es un iniciador (primer en inglés) decámero (ACG GCC CAC C), el cual mostró una banda a 940 bp (banda 421R) en genotipos resistentes y una banda a $900 \mathrm{bp}$ (banda 421S) en los materiales susceptibles a una pequeña distancia de $1,0 \mathrm{cM}$ del gen $\mathrm{Sw}-5$ con una banda polimórfica de tipo co-dominante; es decir, 2 bandas en los genotipos supuestamente heterocigotos (Stevens et ál. 1996). El marcador UBC-421 fue posteriormente convertido en un marcador SCAR (Sequence Characterized Amplified Region) tipo co-dominante (iniciadores Sw-421-1 y 421-2 a 20 bp), un trabajo reciente realizado por Rodrigues do Nascimento et ál. (2009), confirmó la herencia co-dominante del marcador $\mathrm{Sw}-421$ al identificar genotipos resistentes de tomate en progenies isogénicas segregantes. Como Sw-421 muchos otros marcadores moleculares tipo SCAR fueron desarrollados, pero su eficacia aún necesita ser probada en los programas de mejoramiento genético de tomate (Moon y Nicholson 2007, Fooland 2007, Rodrigues do Nascimento et ál. 2009). Convertir marcadores específicos RAPD en marcadores para PCR (Polimeraza Chain Reaction) es deseable porque los marcadores basados en PCR son de fácil uso, menos laboriosos y de bajo costo para ensayar un locus simple y que es más reproducible (Moon 2006, Stevens y Robbins 2007). 
El objetivo del presente estudio fue evaluar la resistencia y susceptibilidad de plantas en híbridos de tomate por evaluación fenotípica y del patrón molecular a través del marcador SCAR (Sw-421), que distingue los homocigotos (Sw-5/ $\mathrm{Sw}-5)$ y heterocigotos $\left(\mathrm{Sw}-5 / \mathrm{Sw}-5^{+}\right)$resistentes del susceptible $\left(\mathrm{Sw}_{-} 5^{+} / \mathrm{Sw}-5^{+}\right)$.

\section{MATERIALES Y MÉTODOS}

El estudio se realizó en la campaña 2012 en el invernadero y laboratorio de biología molecular de la Fundación PROINPA, zona de El Paso, a $15 \mathrm{~km}$ de la ciudad de Cochabamba provincia de Quillacollo del departamento de Cochabamba (Bolivia), comprendido entre los paralelos $17^{\circ} 18^{\prime}$ de latitud Sur y $66^{\circ} 14^{\prime}$ de longitud Oeste, a una altitud de $2540 \mathrm{msnm}$.
Se utilizaron 10 híbridos y 2 parentales de tomate obtenidos en el programa de mejoramiento genético de la Fundación PROINPA (Gabriel et ál. 2012).

\section{QTLs y genes de resistencia conocidos}

Se utilizó el marcador Sw-421 que fue compendiado en una lista de marcadores potenciales que están ligados y co-localizados con el gen de resistencia al tospovirus $\mathrm{Sw}-5$ en un mapa referencial de papa y tomate (Tanskley et ál. 1992, Brommonschenkel y Tanksley 1997, Foolad 2007, Moon y Nicholson 2007, Rodrigues do Nascimento et ál. 2009). En el Cuadro 1 se describe el gen de resistencia a TSWV mientras que en el Cuadro 2 los marcadores en los híbridos para el cribado del gen $\mathrm{Sw}-5$ de resistencia a tospovirus (TSWV) en tomate.

Cuadro 1. Genes de resistencia al TSWV del tomate recopilados en 12 cromosomas, intervalo de marcadores flanqueantes (MF) para el gen.

\begin{tabular}{cccccl}
\hline $\mathrm{N}^{\circ}$ & Crom & Gen & MF & Factor & Referencia \\
\hline 1 & IX & Sw-5 & Sw421 & TSWV & $\begin{array}{l}\text { Rodrigues do Nascimento et ál. (2009), Foolad (2007), Moon y } \\
\text { Nicholson (2007), Brommonschenkel y Tanksley (1997). }\end{array}$ \\
\hline
\end{tabular}

Crom=cromosoma; $\mathrm{MF}=$ marcador flanqueante.

Cuadro 2. Secuencias de los cebadores utilizados para amplificar los correspondientes marcadores en los híbridos para el cribado del gen Sw-5 de resistencia a tospovirus (TSWV) en tomate.

\begin{tabular}{lllccc}
\hline Marcador & Cebador directo & Cebador reverso & $\begin{array}{c}\mathrm{T}^{\circ} \mathrm{A} \\
\left({ }^{\circ} \mathrm{C}\right)\end{array}$ & Tamaño & Protocolo \\
\hline Sw421 & GAC TTG TTG CCA TAG GTT CC & GCC CAC CCC GAA GTT AAT CC & 60 & 940 bp & SCAR \\
\hline
\end{tabular}

SCAR = Sequence Characterized Amplified Region (Secuencia caracterizada de la región amplificada).

\section{Extracción de ADN}

Se colectaron foliolos jóvenes y sanos de 10 híbridos y 2 parentales de tomate, provenientes de invernadero y almacenadas a $-20^{\circ} \mathrm{C}$.

El ADN genómico total fue extraído a partir del material vegetal molido mediante el método CTAB 2X (hexadecil bromuro de trimetil amonio) desarrollado por Doyle y Doyle (1990). La calidad y concentración del ADN obtenido fue evaluado después de la tinción con bromuro de etidio en geles de agarosa al $1 \%$ y transluminador UV marca Biorad. 


\section{Condiciones de la PCR}

Para el análisis de PCR se siguió el protocolo desarrollado por Rodrigues do Nascimento et ál. (2009) con algunas modificaciones, donde la mezcla de reacción contenía 15 ng de ADN genómico, buffer PCR 10X, 0,2 mM dNTP, 1 pmol. $\mu \mathrm{l}^{-1}$ de cada iniciador y $0,025 \mathrm{U} . \mu \mathrm{l}^{-1}$ de la enzima Tag polimeraza.

Las condiciones de reacción consistieron en $94^{\circ} \mathrm{C}$ por $5 \mathrm{~min}, 35$ ciclos de $94^{\circ} \mathrm{C}$ por $1 \mathrm{~min}$, $60^{\circ} \mathrm{C}$ por $45 \mathrm{~s} \mathrm{y} 72^{\circ} \mathrm{C}$ por $60 \mathrm{~s}$. (T100 Thermal Cycler marca BioRad). Los productos de amplificación fueron separados en geles de agarosa.

\section{Análisis de alelos}

La presencia o ausencia del marcador molecular validado en cada híbrido, se anotó y almacenó en archivos con formato EXCEL para su posterior análisis.

\section{Resistencia en plantas}

Se lavaron 10 semillas de cada uno de los híbridos en investigación con solución de Metil1-(butilcarbamoil)-2-bencimidazol-carbamato (Benomyl) y se las colocó en cámara húmeda esto es, cada semilla en una servilleta empapada con agua y se mantuvo cerrado por 6 días a temperatura ambiente. Luego se realizó la siembra en un semillero y cuando las plantas alcanzaron un tamaño entre 10 a $12 \mathrm{~cm}$ en la cuarta semana de la siembra se transplantaron en macetas de $1 \frac{1}{2}$ $\mathrm{kg}$ con tierra esterilizada humedecida en invernadero. Se fertilizó, regó y controlaron las plagas y enfermedades que podrían afectar a las plantas hasta el momento de la inoculación, mediante un fungicida sistémico con base en Propiconazole y Difenoconazole (Taspa- 0,5 cc. $^{-1}$ ) y un insecticida con base en Lambda-cihalotrina (Karate-1 cc. $\mathrm{l}^{-1}$ ).

\section{Inoculación}

Para el experimento se utilizaron 65 plantas sanas de tomate con 90 días de edad distribuidas en 13 sub-grupos de 5 plantas cada una. Para la inoculación del virus se siguió el protocolo recomendado por López et ál. (2003).

Como testigos se utilizaron 6 plantas entre las mismas accesiones, las cuales se trataron únicamente con el abrasivo y el buffer fosfato, y se las mantuvo en otro invernadero durante todo el experimento.

Se realizó la serología a 3 plantas infectadas y con sintomatología en invernadero, y se confirmó un DAS-ELISA positivo (+) para una única planta, las otras 2 presentaron resultado negativo (-). Con base en estos resultados se volvió a extraer el inóculo solo de la planta confirmada y se efectuó una segunda inoculación a los 7 días después la primera inoculación y una tercera inoculación a los 9 días.

\section{Análisis de la severidad}

En las plantas inoculadas en invernadero se realizaron evaluaciones de severidad con la escala recomendada por López et ál. (2003) para ubicar las características de severidad de sintomatología producida por TSWV (Cuadro 3).

Cuadro 3. Escala de severidad de sintomatología producidos por TSWV.

\begin{tabular}{cl}
\hline Escala & Características \\
\hline 0 & Ausencia de Sintomatología. \\
1 & Leve detención de crecimiento. Epinastía. Moteado y bronceado en hojas. \\
2 & Moderada detención de crecimiento. Epinastía. Mosaico. Anillos necróticos. \\
3 & Severa detención del crecimiento. Aspecto de rigidez. Epinastía. Mosaico. Anillos necróticos. \\
4 & Severa detención del crecimiento. Epinastía. Variegado y clorosis en hojas. Necrosis en hojas y tallos.
\end{tabular}

Los días de evaluación fueron los siguientes: 2, 9, 13, 16, 20, 24, y 34 ddi. 


\section{Análisis serológico por DAS-ELISA}

\section{Inoculación}

El inoculo, con TSWV previamente identificado por DAS-ELISA, se preparó por maceración de hojas sintomáticas en una dilución de 1/10 (P/V) en tampón fosfato $0,01 \mathrm{M}$ con Sulfito de $\mathrm{Na}$ al $0,1 \%$ y pH 7,22 con adición final de carburundum. El inoculo se mantuvo en un baño de hielo durante todo el proceso de la inoculación (López et ál. 2003).

Se realizó el análisis serológico en 65 plantas inoculadas con síntomas de TSWV y en 5 plantas testigo, mediante el DAS-ELISA (Double Antibody Sándwich - enzyme linked immunosorbent assay). Se llevo a cabo un análisis serológico para GRSV y TSCV en las mismas plantas. Se utilizaron antisueros de la línea AGDIA.

Se colectaron $2 \mathrm{~g}$ de 5 plantas por híbrido, obteniéndose un total de 14 muestras para la prueba.

Para sensibilizar la placa se disolvió 0,146 g de $\mathrm{NAHCO}_{3}$ y $0,079 \mathrm{~g}$ de $\mathrm{NA}_{2} \mathrm{CO}_{3}$ para $11 \mathrm{con}$ $0,010 \mathrm{~g} \mathrm{de} \mathrm{NaN}_{3}$ y finalmente se agregó $100 \mu \mathrm{l}$ de la gamma globulina purificada y se incubó a $4^{\circ} \mathrm{C}$ toda la noche.

\section{Preparación de las muestras para su análisis}

Según protocolo del fabricante la muestra se utilizó en relación 1:4 (Cuadro 4). Se utilizó $100 \mu \mathrm{l}$ de la muestra diluida y testigos (Blanco y control para TSWV).

Se incubó la placa con los antígenos a $4^{\circ} \mathrm{C}$ toda la noche, se adicionó el conjugado en

Cuadro 4. Preparación del buffer de maceración.

\begin{tabular}{lc}
\hline Reactivo & Cantidad \\
\hline Sulfito de Sodio & $0,195 \mathrm{~g}$ \\
PVP & $3,0 \mathrm{~g}$ \\
Azida de Sodio & $0,03 \mathrm{~g}$ \\
Albumina de Huevo & $0,3 \mathrm{~g}$ \\
PBS-tween & $1 \mathrm{ml}$ \\
Agua destilada & c.s.p $150 \mathrm{ml}$ \\
\hline
\end{tabular}

dilución 1:200, luego se añadió la enzima-gamma globulina e incubó a $25^{\circ} \mathrm{C}$ por $2 \mathrm{~h}$, finalmente el sustrato disuelto en buffer de concentración 0,5 mg.ml ${ }^{-1}$ se incubó a temperatura ambiente por 30 min. Las lecturas se realizaron a $450 \mathrm{~nm}$ en lector de ELISA.

\section{RESULTADOS}

\section{Análisis de la resistencia}

Los resultados mostraron que los híbridos cuyo padre fue la especie silvestre 70 89R Sw-5/ Sw-5 (Solanum peruvianum) portador del gen Sw-5 en estado homocigoto transfirió exitosamente el gen de resistencia a TSWV (Cuadro 5). Cabe mencionar que tampoco se observaron síntomas típicos de GRSV y TCSV, lo cual se confirmó con la prueba de DAS-ELISA que no detectó la presencia de estos virus (Cuadro 5).

Se observó que el híbrido PROINPA 7 (Platus x 71 89S LACHING Sw-5) mostró un síntoma leve de atrofiamiento en el crecimiento (escala 1) y fue positivo en la prueba de DASELISA con un valor de 0,139 de absorbancia (Cuadro 5), dicho aspecto indica que este híbrido fue susceptible a TSWV. En cambio, el híbrido PROINPA 6 (Martha x 71 89S LACHING Sw-5), no mostró síntomas de severidad a TSWV, y no reaccionó en la prueba de DAS-ELISA, lo que señala que probablemente éste híbrido tiene algún grado de resistencia y el gen está en estado heterocigótico (Sw-5/Sw-5+) (Cuadro 6), pero si mostró reacción al GRSV y TCRV (Cuadro 5), lo que denota que tuvo susceptibilidad a ambos tipos de virus.

\section{Análisis molecular \\ La temperatura de hibridación (Tm) del iniciador al ADN genómico se realizó en una PCR de gradiente, determinándose una Tm de $60^{\circ} \mathrm{C}$ como la más optima y en la cual se logró una mejor amplificación, visualizándose la banda de interés para el marcador Sw-421 a los 940 bp.}




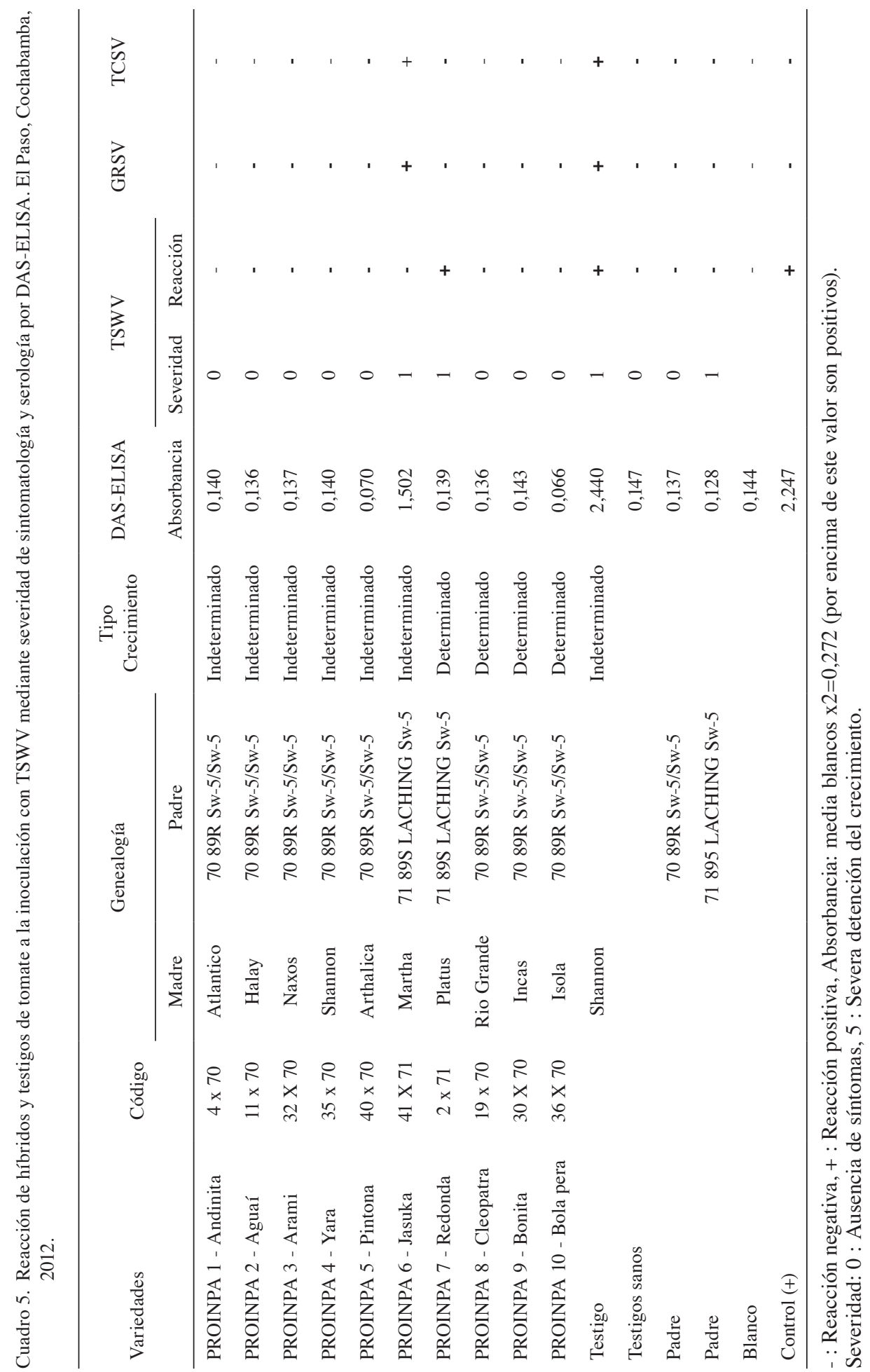


Cuadro 6. Pares de bases y estado de los genes de las diferentes variedades híbridas de tomate. El Paso, Cochabamba, 2012.

\begin{tabular}{|c|c|c|c|c|c|}
\hline \multirow{2}{*}{ Variedad } & \multirow{2}{*}{ Código } & \multicolumn{2}{|r|}{ Genealogía } & \multirow{2}{*}{$\mathrm{bp}$} & \multirow{2}{*}{ Genes } \\
\hline & & Hembra & Macho & & \\
\hline PROINPA 1 - Andinita & $4 \times 70$ & Atlantico & 70 89R Sw-5/Sw-5 & $900-940$ & Sw-5/Sw- $5^{+}$ \\
\hline PROINPA 2 - Aguaí & $11 \times 70$ & Halay & 70 89R Sw-5/Sw-5 & 940 & Sw-5/Sw-5 \\
\hline PROINPA 3 - Arami & $32 \times 70$ & NAXOS & 70 89R Sw-5/Sw-5 & $900-940$ & Sw- $5 / \mathrm{Sw}-5^{+}$ \\
\hline PROINPA 4 - Yara & $35 \times 70$ & Shannon & 70 89R Sw-5/Sw-5 & 940 & Sw- $5 / \mathrm{Sw}-5^{+}$ \\
\hline PROINPA 5 - Pintona & $40 \times 70$ & Arthalica & 70 89R Sw-5/Sw-5 & $900-940$ & Sw- $5 / \mathrm{Sw}-5^{+}$ \\
\hline PROINPA 6 - Jasuka & $41 \times 71$ & Martha & 71 89S LACHING SW-5 & $900-940$ & Sw- $5 /$ Sw- $5^{+}$ \\
\hline PROINPA 7 - Redonda & $2 \times 71$ & Platus & 71 89S LACHING SW-5 & 900 & $\mathrm{Sw}-5^{+} / \mathrm{Sw}-5^{+}$ \\
\hline PROINPA 8 - Cleopatra & $19 \times 70$ & Rio Grande & 70 89R SW-5/SW-5 & $900-940$ & Sw- $5 / \mathrm{Sw}-5^{+}$ \\
\hline PROINPA 9 - Bonita & $30 \times 70$ & INCAS & 70 89R SW-5/SW-5 & 940 & Sw-5/Sw-5 \\
\hline PROINPA 10 - Bola pera & $36 \times 70$ & ISOLA & 70 89R SW-5/SW-5 & $900-940$ & Sw- $5 / \mathrm{Sw}-5^{+}$ \\
\hline 89R SW-5/SW-5 & & & & 940 & $\mathrm{Sw}-5 / \mathrm{Sw}-5$ \\
\hline 895 LACHING SW-5 & & & & 900 & $\mathrm{Sw}-5^{+} / \mathrm{Sw}-5^{+}$ \\
\hline Shannon & & & & 900 & $\mathrm{Sw}-5^{+} / \mathrm{Sw}-5^{+}$ \\
\hline
\end{tabular}

Sw-5/Sw-5: Homocigoto dominante resistente, Sw-5 $/ \mathrm{Sw}-5^{+}$: Homocigoto recesivo susceptible, Sw-5/Sw-5 resistente, PROINPA 1 al PROINPA 6: Plantas Indeterminadas, PROINPA 7 a PROINPA 10: Plantas Determinadas.

El análisis molecular (Figura 1 y Cuadro 6) mostró que las variedades PROINPA 2 (Aguaí), y PROINPA 9 (Bonita) tienen el gen de resistencia (R) a TSWV en estado homocigoto dominante (Sw-5/Sw-5) y se la encontró a los 940 bp. Las variedades PROINPA 1 (Andinita), PROINPA 3 (Arami), PROINPA 4 (Yara), PROINPA 5 (Pintona), PROINPA 6 (Jasuka), PROINPA 8 (Cleopatra) y PROINPA
10 (Bola pera), tienen el gen de resistencia $(\mathrm{H})$ a TSWV en estado heterocigoto $\left(\mathrm{Sw}-5 / \mathrm{Sw}-5^{+}\right)$ y se las ubicó entre 900-940 bp. Solamente en la variedad PROINPA 7 (Redonda), el padre 71 89S LACHING Sw-5 y la variedad Shannon, presentaron el gen de susceptibilidad (S) al TSWV en estado homocigoto recesivo $\left(\mathrm{Sw}_{-} 5^{+}\right.$ Sw- $5^{+}$) y se la detectó a 900 bp.

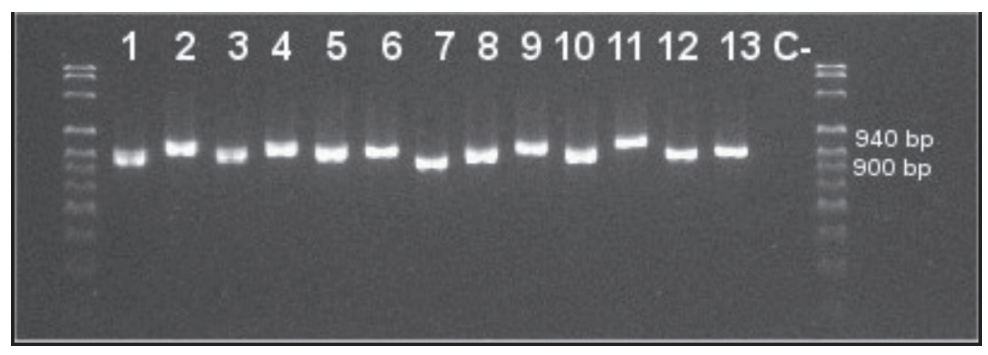

1: Proinpa 1 (Andinita), 2: Proinpa 2 (Aguaí), 3: Proinpa 3 (Arami), 4: Proinpa 4 (Yara), 5: Proinpa 5 (Pintona), 6: Proinpa 6 (Jasuka), 7: Proinpa 7 (Redonda), 8: Proinpa 8 (Cleopatra), 9: Proinpa 9 (Bonita), 10: Proinpa 10 (Bola pera), 11. Parental 89R Sw-5/Sw-5, 12: Parental 895 LACHING SW-5, 13: Shannon; C-: Control negativo de reacción, bp: pares de bases.

Fig. 1. La identificación visual de las bandas se realizó en un gel de agarosa al 1,8\% en un transluminador UV marca Biorad. 


\section{DISCUSIÓN}

El método de ADN con el uso de CTAB, fue eficiente y conveniente para la extracción a partir de pequeñas muestras de tejido (Ferreira y Grattapaglia 1998), lo cual se evidenció por el alto nivel diferenciación en las bandas encontradas con el iniciador utilizado, obteniéndose ADN de buena calidad, libre de contaminantes, libre de ARN, no degradado, y con alto peso molecular. La temperatura de hibridación para la amplificación se ajusto a $60^{\circ} \mathrm{C}$, que difiere a los reportados por Nascimento et ál. (2009) y Erico et ál. (2009), lo que es indicativo que se requieren mejoras de los protocolos en cada laboratorio.

Cabe mencionar que investigaciones realizadas por Boiteux y De Giordano (1993) encontraron que el mismo gen de resistencia al TSWV le confiere resistencia a GRSV y TCSV, lo cual nos hace ver la gran importancia de incorporar genes de especies silvestres emparentadas con el tomate. En nuestra investigación los análisis han mostrado que aparentemente se ha logrado el control efectivo de los 3 virus con el gen Sw-5 introducido de Solanum peruvianum en algunos de los híbridos evaluados.

También se identifica que la enfermedad evoluciona y como solución más práctica se identifica la necesidad de buscar y seleccionar nuevas fuentes de material con resistencia natural contra las nuevas variantes de TSWV. En este sentido, esta investigación ha procurado obtener nuevas fuentes de resistencia, mediante inoculación mecánica de aislados virales que superan la resistencia, en entradas de diferentes especies silvestres relacionadas con el tomate cultivado (Peralta et ál. 2007). Así, se recomienda ensayar el uso de accesiones de las especies Solanum habrochaites, S. chilense, S. pennellii, S. peruvianum y $S$. pimpinellifolium (Peralta et ál. 2007). En el futuro se espera determinar el control genético de estas resistencias para, transferir luego, los genes responsables, a variedades de tomate de interés agronómico.

Por otra parte también se observó que la evaluación fenotípica confirmó la eficiencia en el proceso de inoculación y mostro reacción diferencial de los genotipos de acuerdo con la presencia o ausencia del alelo Sw-5. El marcador molecular permitió la identificación de homocigotos $\mathrm{Sw}-5 / \mathrm{Sw}-5$ y heterocigotos $\mathrm{Sw}-5 / \mathrm{Sw}-5^{+}$en las plantas resistentes, resultados similares a los encontrados por Rodrigues do Nascimento et ál. (2009) al evaluar progenies isogénicas segregantes de tomate.

\section{AGRADECIMIENTOS}

Se agradece al apoyo económico de los proyectos: Fontagro - Desarrollo y valoración de recursos genéticos de Lycopersicon spp., para su utilización en mejoramiento genético de Solanáceas frente a estrés biótico y abiótico (ID: 8071) y "Fortaleciendo capacidades de innovación participativa para luchar contra la pobreza rural" (IP - Holanda).

\section{LITERATURA CITADA}

ABAD J.A., MOYER J.W., KENNEDY G.G., HOLMES G.A., CUBETA M.A. 2005. Tomato spotted wilt virus on potato in Eastern North Carolina. American Journal of Potato Research 82:255-261.

BOITEUX L.S., DE GIORDANO L.B. 1993. Genetic basis of resistance against two Tospovirus species in tomato (Lycopersicon esculentum). Euphytica 71:151-154.

BROMMONSCHENKEL S.H., TANKSLEY S.D. 1997. Map-based cloning of the tomato region that spans the $\mathrm{Sw}-5$ tospovirus resistance gene in tomato. $\mathrm{Mol}$ General Genet 256:121-126.

DOYLE J.J., DOYLE J.L. 1990. A rapid total DNA preparation procedure for fresh plant tissue. Focus 12:13-15.

ERICO C.D., FONSECA M.N., GOLDBACH R. 2009. Development of a locus-specific, co-dominant SCAR marker for assisted-selection of the Sw-5 (Tospovirus resistance) gene cluster in a wide range of tomato accessions. Springer Science Business 25:133-142.

FERRAZ E., RESENDE L.V., LIMA G.S.A., SILVA M.C., FRANÇA J.G.E., SILVA D.J. 2004. Redenção: nova cultivar de tomate para a indústria resistente a geminivírus e tospovírus. Horticultura Brasileira 21:578-580.

FERREIRA M.E., GRATTAPAGLIA D. 1998. Introducción al uso de marcadores moleculares en el análisis genético. 1 ed. Brasilia, EMBRAPA-CENARGEN, documento 20.220 p. 
FOOLAD M.R. 2007. Genome mapping and molecular breeding of tomato. International Journal of Plant Genomics. 52 p.

GABRIEL J., LÓPEZ E., MAGNE J., ANGULO A., LUJÁN R., CRESPO M. 2012. Combining ability of tomato hybrids (Solanum lycopersicum) under geenhouse condition. J. Selva Andina Res. Soc. Bolivia 12 p.

GARCIA P.E., LOZOYA G.E. 2004. Genes de resistencia a enfermedades en plantas. Revista Mexicana Fitopatología 22:414-422.

JULIATTI F.C., MALUF W.R. 1995. Controle genético da resistência do tomateiro a um isolado de tospovirus (TSVW): análise de plantas individuais. Fitopatologia Brasileira 20:39-47.

LAU D., OLIVEIRA J.C.F., LAU E.Y., BROMMONSCHENKEL S.H. 2006. Hipersensibilidade e necrose sistêmica em Nicotiana benthamiana transformada com o gene de resistência Sw-5 de tomateiro. Fitopatologia Brasileira 31:247-253.

LIMA G.S.A., LAU D., PICOLI E.A.T., ASSUNÇÃO I.P., BROMMONSCHENKEL S.H., OTONI W.C. 2002. Reação de genótipos de berinjela a quatro espécies de tospovírus. Summa Phytopathologica 28:242-247.

LÓPEZ P., BIDERBOST E., DI FEO L., MOLLINEDO V.A. 2003. Relación entre concentración viral y la tolerancia al TSWV determinada por el gen "platense" en tomate. Fitopatología (Perú) 1(38):23-31.

MOON H. 2006. Identification of AFLP markers linked to tomato spotted wilt virus resistance in tobacco. Raleigh: North Carolina State University. Dissertation (PhD). $91 \mathrm{p}$.

MOON H., NICHOLSON J.S. 2007. AFLP and SCAR markers linked to tomato spotted wilt virus resistance in tobacco. Crop Breeding y Genetics 47:1887-1894.

PERALTA I.E., SPOONER D.M. 2007. History, origin and early cultivation of tomato (Solanaceae), pp. 1-24. In: M.K. Razdan and A.K. Mattoo (eds.). Genetics improvement of Solanaceus crops; volume 2: Tomato. Science Publishers, Enfield, NH, USA.

PLATA G. 2011. Caracterización de enfermedades virales en el cultivo de tomate (Solanum lycopersicum) bajo condiciones de invernadero. Tesis de maestria, Posgrado, Facultad de Ciencias Agricolas y Pecuarias "Martín Cárdenas", UMSS, Cochabamba, Bolivia. 104 p.

RIBEIRO A.L., PINTO C.A.B.P., ANDRADE C.M., SANTOS J.B., FIGUEIRA A.R. 2006. SCAR marker for the selection of Ry-duplex potato clones immune to potato virus Y. Crop Breeding and Applied Biotechnology, v. 1, p.1-9.
ROBERTSON L.D., LABATE J.A. 2007. Genetic resources of tomato (Lycopersicum sculentum Mill.) and wild relatives, pp. 26-76. In: M.K. Razdan and A.K. Mattoo (eds.). Genetics improvement of Solanaceous crops; volume 2: Tomato. Science Publishers, Enfield, NH, USA.

RODRIGUES DO NASCIMENTO I., MALUF W., FIGUEIRA A., MENEZES C., VILELA DE RESENDE J., FARIA M., WILLIAN D. 2009. Marker assisted identification of tospovirus resistant tomato genotypes in segregating progenies. Scientia Agricola (Piracicaba, Braz.) 3(66):298-303.

ROSELLO S., DÍEZ M.J., NUEZ F. 1998. Genetics of tomato spotted wilt virus resistance coming from Lycopersicon peruvianum. European Journal Plant Pathology 104:499-509.

SANTOS R.C. 2004. Reação de cultivares de soja aos vírus do amarelo do broto (Soybean yellow shoot vírus- SYSV) e do mosaico da soja (Soybean mosaic vírus - SMV) e seleção de marcadores SSR para identificação do alelo de resistência ao SYSV.Tese Doutorado, Universidade Federal Lavras, Lavras, Brasil. 77 p.

SILVA G.F., SANTOS J.B., RAMALHO M.A.P. 2003 Identification of SSR and RAPD markers linked to a resistance allele for angular leaf spot in the common bean (Phaseolus vulgaris) line ESAL 550. Genetics and Molecular Biology 26:459-463.

STEVENS M.R., HEINY D.K., RHOADS D.D., GRIFFITHS P.D., SCOTT J.W. 1996. A linkage map of the tomato spotted wilt virus resistance gene $\mathrm{Sw}-5$ using near isogenic lines and an interspecific cross. Acta Horticulturae 431:385-392.

STEVENS M.R., ROBBINS M.D. 2007. Molecular markers in selection of tomato germplasm, pp. 239-260. In: M.K. Razdan and A.K. Mattoo (eds.). Genetics improvement of Solanaceus crops; volume 2: Tomato. Science Publishers, Enfield, NH, USA.

STEVENS M.R., SCOTT S.J., GERGERICH R.C. 1992 Inheritance of a gene for resistance to tomato spotted wilt virus (TSWV) from Lycopersicon peruvianum Mill. Euphytica 59:9-17.

TANSKLEY S.D., GANAL M.W., PRINCE J.P., DE VICENTE M.B., BONIERBALE M.W., BOUN P., FULTON P.M., GIOVANNONI J.J., GANDILLO S., MARTIN G.B., MESSESGUER R., MILLER J.C., MILLER L., PATERSON A.H., PINEDA O., RODER M., WING R.A., WU W., YOUNG N.D. 1992. High density molecular linkage maps of the tomato and potato genome; biological inferences and practical applications. Genetics 132:1141-1160.

Todos los derechos reservados. Universidad de Costa Rica. Este artículo se encuentra licenciado con Creative Commons Reconocimiento-NoComercial-SinObraDerivada 3.0 Costa Rica. Para mayor información escribir a rac.cia@ucr.ac.cr 
